\title{
Epidemiological and Pathologic Characteristics of Cancer Morbidity in Elderly Nigerians: A Call for Action
}

\section{Obiora Jude Uchendu ${ }^{1}$, Obahiagbon Ikponmwosa ${ }^{2}$}

${ }^{1}$ Department of Histopathology, Delta State University, Abraka, Nigeria ${ }^{2}$ Department of Anatomical Pathology, University of Benin Teaching Hospital, Benin City, Edo State, Nigeria.

\begin{abstract}
Objective: Geriatric cancer is a major public health problem with increasing incidence due to population growth and ageing. This study hopes to analyze the epidemiology and pathology of geriatric cancer in a Nigerian tertiary healthcare center. Method: The study is a ten-year (2010-2019) descriptive retrospective study of histopathologically confirmed geriatric cancer cases in the University of Benin Teaching Hospital, Nigeria. The age, gender, anatomic site and histological diagnosis were used for the study. Analysis was with Microsoft Excel spreadsheet and results summarized in tables and figures. Result: Geriatric cancer accounted for $33.7 \%$ of all cancers, affecting 871 males and 593 females with mean age and age range of 70.4 and 60-101 years respectively. Cases in 2010, 2011, 2012, 2013, 2014, 2015, 2016, 2017, 2018 and 2019 were $7.9 \%, 10.5 \%, 10.7 \%, 11.3 \%, 7.0 \%$, $8.5 \%, 8.55 \%, 10.5 \%, 11.8 \%$ and $12.4 \%$ respectively. Exactly $26.0 \%, 25.4 \%, 19.1 \%, 15.0 \%, 9.0 \%, 3.2 \%, 1.3 \%$, $0.8 \%$, and $0.2 \%$ of cancer cases were encountered among the $60-64,65-69,70-74,80-84,85-89,90-94,95-99$ and 100-104 years age groups respectively. Prostate, cervical, breast, colorectal and gastric cancer accounted for $41.3 \%, 12.3 \%, 12.3 \%, 5.8 \%$ and $3.1 \%$ of the cases respectively. Conclusion: Geriatric cancer incidence is on the increase with male predominance and a peak at $60-64$ years. About $75 \%$ of geriatric cancer affected the prostate, uterine cervix, breast, stomach and colorectum. Geriatric cancer care is still a low priority in Nigeria. A stronger health and social system is desirable for the worsening geriatric cancer burden in this region.
\end{abstract}

Keywords: Elderly- age- cancer- histopathology- prevention

Asian Pac J Cancer Care, 5 (4), 295-302

\section{Introduction}

Cancer is a major public health and socioeconomic challenge worldwide, affecting all age groups [1]. It is generally seen as a disease of old age because it is usually driven by age-related accumulation of mutations and carcinogenesis, decreased capacity to repair genetic damage and greater tissue sensitivity to these carcinogenic agents [2]. In developed countries, over $60 \%$ of cancer and about $70 \%$ of cancer related mortality are encountered among the 65+ years age group [3]. Geriatric cancer has been associated with more aggressive cancer biology, increased risk of treatment toxicity, co-morbidities, decreased physiological reserve, reduced access to health care, and ultimately higher cancer death rate relative to cancer in the younger counterparts [4]. As the world continues to experience a demographic shift, due to
Submission Date: 07/24/2020Ａcceptance Date: 11/08/2020

\footnotetext{
Corresponding Author:

Dr. Obiora Jude Uchendu

Department of Histopathology, Delta State University, Abraka, Nigeria.

Email: ojlinksent@yahoo.com
}

improvement in living standard and advances in medical care, the number of elderly patients with cancer will continue to rise, further increasing the global burden of cancer [5].

In Nigeria, there are only few and sub-optimal population-based cancer registries and the quality of cancer data from these regions are usually poor [6]. These challenges invariably obscure the true picture of geriatric cancer morbidity and mortality. With a relatively low life expectancy and with only about $3.0 \%$ of the population within the age range of 65 years and above,[7] the choice of the $60+$ years age group as the definition of the Nigerian elderly is justified [8].

The pattern and trend of cancer morbidity in Nigerian elders is scarcely addressed in existing literature. 
In this paper, we analyzed data from the histopathology department of one of the apex tertiary care centers in Nigeria with the hope of describing the epidemiological and histopathological characteristics of geriatric cancer in this region. It is hoped that findings from this study will close the knowledge gap and guide health policy makers, legislators, public health educators and clinical researchers in taking the necessary action in preventing cancer and improving the healthcare of elderly patients with cancer.

\section{Materials and Methods}

University of Benin Teaching Hospital (UBTH) is the apex reference tertiary care center in Edo State of the South-southern part of Nigeria with a capacity of over 600 bed spaces. It is also one of the few hospitals with histopathology and immunohistochemistry services in this region.

The index study is a hospital-based descriptive retrospective study carried out in the Department of Pathology, UBTH, Nigeria, from $1^{\text {st }}$ January 2010 to $31^{\text {st }}$ December 2019.

The materials for this study included duplicate copies of the histopathology reports, histopathology slides, and tissue blocks of all confirmed cancer cases of patient aged 60 years and above during the study period.

The data retrieved included the age and sex of patients, site of lesion and corresponding histological diagnosis. The sites of the cancer were reclassified using ICD10 classification of cancer [9]. Where necessary, fresh tissue sections were made and re-examined under the microscope. Special histochemical and immunohistochemical stains were utilized when necessary, to confirm challenging cases.

Data analysis was done using Excel spreadsheet 2007 and the statistical summary presented in Tables and Figures.

\section{Results}

In ten years, we had 4344 histologically confirmed cancer cases, out of which 1464 cases $(33.7 \%)$ were patients of $60+$ years. The average incidence is 146.4 cancer cases per annum. Of these patients, 871 (59.5\%) were males while 593 (40.5\%) were females, which gave a male to female ratio of $1.5: 1$. The age of the patients ranged from 60-101 years with a mean age of 70.4 years. The elderly male and female mean ages were 71.3 and 69.0 years respectively.

The yearly distribution of cancer among the older patients is shown in Table 1 with $7.9 \%, 10.5 \%, 10.7 \%$, $11.3 \%, 7.0 \%, 8.5 \%, 8.55 \%, 10.5 \%, 11.8 \%$ and $12.4 \%$ of cases recorded in 2010, 2011, 2012, 2013, 2014, 2015, 2016, 2017, 2018 and 2019 respectively. This is depicted in Figure 1.

The age distribution of cancer among older adults is shown in Figure 2. Among the males, 20.9\%, 23.3\%, $23.0 \%, 17.1 \%, 9.8 \%, 4.0 \%, 1.5 \%, 0.3 \%$ and $0.2 \%$ of the cancer cases were encountered in the 60-64, 65-69, 70-74, $80-84,85-89,90-94,95-99$ and $100-104$ years age groups respectively. The relative proportions of the cancer cases in older females were as follows: 60-64 years (33.6\%), 65-69 years $(28.5 \%), 70-74$ years $(13.5 \%), 75-79$ years $(12.0 \%), 80-84$ years $(7.9 \%), 85-89$ years $(2.0 \%), 90-94$ years $(1.0 \%)$, 95-99 years $(1.4 \%)$ and $100-104$ years $(0.2 \%)$. Among both genders, $26.0 \%, 25.4 \%, 19.1 \%$, $15.0 \%, 9.0 \%, 3.2 \%, 1.3 \%, 0.8 \%$, and $0.2 \%$ of cancer cases were encountered in the 60-64, 65-69, 70-74, 80-84, 85-89, 90-94, 95-99 and 100-104 years age groups respectively.

Details of the organ distribution of geriatric cancer by gender are shown in Table 1. The most common cancer among males in descending order were prostate $(69.4 \%)$, colorectal $(4.8 \%)$, laryngeal $(2.8 \%)$, stomach $(2.8 \%)$, nose and paranasal sinuses $(2.6 \%)$ and bladder cancer $(2.3 \%)$. Leading cancer in older women were cervical $(30.4 \%)$, breast $(27.5 \%)$, colorectal $(7.3 \%)$, corpus uteri (4.4\%) and stomach (3.7\%) cancers. Among all geriatric cancer, prostate $(41.3 \%)$, cervical $(12.7 \%)$, breast $(12.3 \%)$, colorectal $(5.8 \%)$ and stomach cancer $(3.1 \%)$ are the leading cancer.

Details of regional distribution of cancer among the different age groups is shown in Table 2.

Table 3 and 4 compared the distribution of the top five geriatric cancer across the globe with the present study. Figure 3 show the distribution of the cancer into

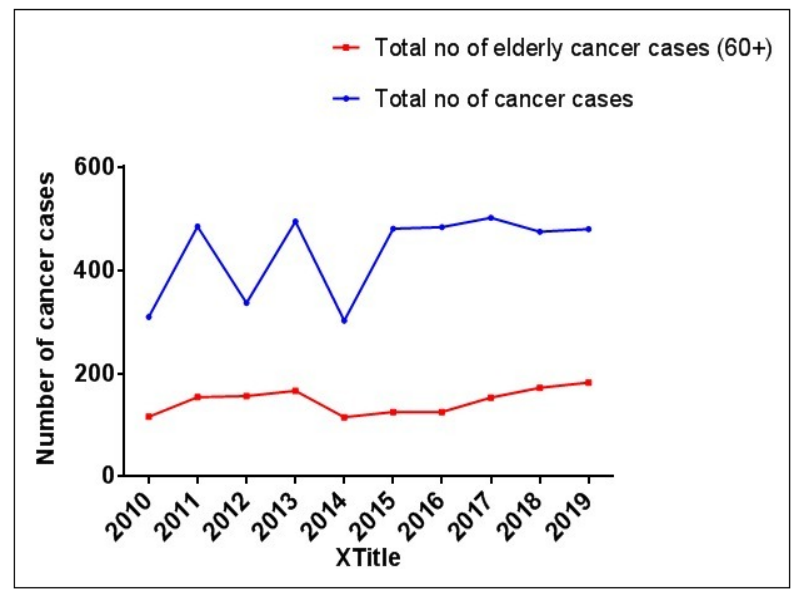

Figure 1. Yearly Trend of Geriatric Cancer in Nigeria

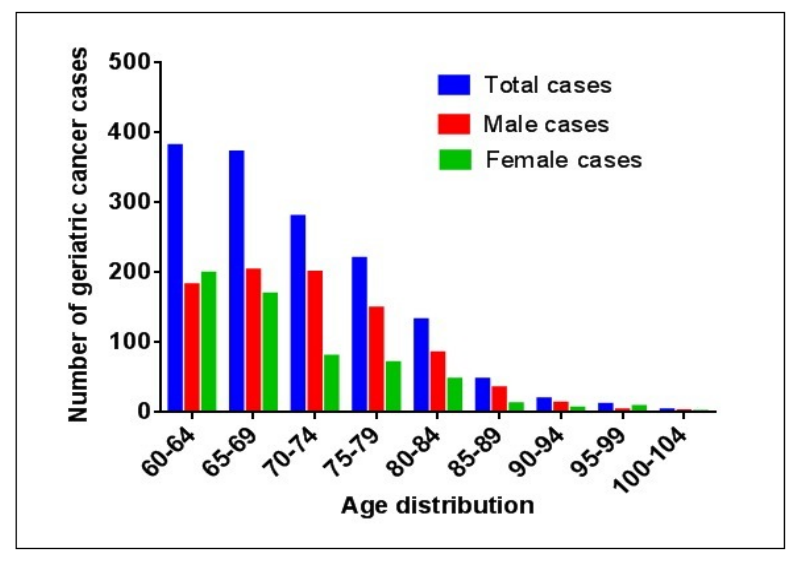

Figure 2. Age-wise Distribution of Geriatric Cancer in Nigeria 
the major histological groups with carcinomas, sarcomas, lymphomas, mixed tumours and blastomas accounting for $94.7 \%, 2.7 \%, 2.3 \% .0 .1 \%$ and $0.1 \%$ of the cases respectively.

\section{Discussion}

To the best of our knowledge, this is the first epidemiological and pathologic assessment of the burden of geriatric cancer in this part of the globe. The strength of the analysis lies in the long duration of the study, the reliable diagnostic technique utilized, and the large population served by the hospital. The findings from this study will further strengthen already existing record from Nigerian cancer registries.

In this study, geriatric cancer accounted for $34.5 \%$ of all histopathologically confirmed cancer cases in the study center which concurred with earlier reports from other parts of Nigeria, namely Port Harcourt (37.1\%) [10] and Akwa Ibom (37.4\%) [11]. In a report from both Ibadan and
Abuja cancer registries, $38 \%$ of the cancer cases involved patients from the age of 55 years [12]. In Ghana [13] and Togo [14]. $36 \%$ and $15.2-17.4 \%$ of cancer patients respectively were of $60+$ years old. These proportions from the African setting were however lower than $60 \%$ reported among Chinese,[15] United States of America (US) [16] and European elderly [17]. Nigeria currently has a relatively younger population structure with so many barriers limiting the access of older adults to healthcare [7]. With improvements in the socioeconomic structure and the quality of medical care, and current population growth, the proportion of older adults in the country is bound to increase, resulting in a corresponding increase in geriatric cancer burden in the future. This development could exert substantial pressure on our health system unless necessary changes are implemented.

In this study, we observed a gradual increase in the number of geriatric cancer cases up to the year 2013. A sharp decline was noted in 2014, and afterwards, a continuous rise till date. It is important to note that

Table 1. Gender and Topographic Incidence of Geriatric Cancer in Nigeria

\begin{tabular}{|c|c|c|c|c|c|c|c|c|c|}
\hline \multirow[t]{2}{*}{ SITE/ORGAN } & \multicolumn{3}{|c|}{ Male } & \multicolumn{3}{|c|}{ Female } & \multicolumn{3}{|c|}{ All Cases } \\
\hline & No & Percentage (\%) & Mean age (yrs) & No & Percentage (\%) & Mean age (yrs) & No & Percentage (\%) & Mean age (yrs) \\
\hline Prostate & 604 & $(69.40)$ & 72.3 & & & & 604 & $(41.30)$ & 72.3 \\
\hline Cervix & & & & 180 & (30.40) & 69.2 & 180 & (12.30) & 69.2 \\
\hline Breast & 17 & $(2.00)$ & 71.8 & 163 & $(27.50)$ & 67.3 & 180 & (12.30) & 67.7 \\
\hline Colorectum & 42 & $(4.80)$ & 68.6 & 43 & (7.30) & 69.9 & 85 & $(5.80)$ & 69.2 \\
\hline Stomach & 24 & $(2.80)$ & 72.5 & 22 & (3.70) & 72.1 & 46 & (3.10) & 72.4 \\
\hline Nose, sinuses & 23 & (2.60) & 69.1 & 13 & $(2.20)$ & 67.2 & 36 & $2.50)$ & 68.9 \\
\hline Bladder & 20 & (2.30) & 69.7 & 13 & $(2.20)$ & 72.3 & 33 & $(2.30)$ & 70.7 \\
\hline Skin non melanoma & 17 & $(2.00)$ & & 13 & $(2.20)$ & 73.2 & 30 & $((2.10)$ & 70.7 \\
\hline Uterine corpus & & & & 26 & $(4.40)$ & 66.8 & 26 & $(1.80)$ & 66.8 \\
\hline Larynx & 24 & $(2.80)$ & 67.8 & 1 & & 60 & 25 & (1.70) & 67.4 \\
\hline Lung & 11 & $(1.30)$ & 67.5 & 11 & $(1.90)$ & 68.9 & 22 & $(1.50)$ & 68.2 \\
\hline NHL & 9 & $(1.00)$ & 69.1 & 18 & $(3.00)$ & 66.3 & 27 & $(1.80)$ & 67.5 \\
\hline Esophagus & 10 & $(1.20)$ & 66.8 & 8 & (1.40) & 70.3 & 18 & $(1.20)$ & 68.3 \\
\hline Kaposi & 15 & $(1.70)$ & 67.5 & 3 & $(0.50)$ & 65.7 & 18 & $(1.20)$ & 67.2 \\
\hline Ovary & & & & 16 & $(2.70)$ & 67.9 & 16 & (1.10) & 67.9 \\
\hline Soft tissue & 11 & $(1.30)$ & 69.7 & 4 & $(0.70)$ & 70.5 & 15 & $(1.00)$ & 69.9 \\
\hline Vulva & & & & 12 & $(2.00)$ & 69.3 & 12 & $(0.80)$ & 69.3 \\
\hline Skin melanoma & 5 & $(0.60)$ & 65.6 & 5 & $(0.80)$ & 77.4 & 10 & (0.7) & 71.5 \\
\hline Liver & 3 & $(0.30)$ & 65.7 & 6 & $(1.00)$ & 66 & 9 & $(0.60)$ & 65.9 \\
\hline Kidney & 2 & $(0.20)$ & 65 & 6 & $(1.00)$ & 74.3 & 8 & $(0.60)$ & 72 \\
\hline Thyroid & 3 & $(0.30)$ & 65.7 & 5 & $(0.80)$ & 72 & 8 & $(0.60)$ & 72.2 \\
\hline Hypopharynx & 5 & $(0.60)$ & 66.8 & 1 & $(0.20)$ & 66 & 6 & $(0.40)$ & 66.7 \\
\hline Salivary gland & 1 & $(0.10)$ & 69 & 3 & $(0.50)$ & 70.3 & 4 & $(0.30)$ & 70 \\
\hline Small intestine & & & & 4 & $(0.70)$ & 74.5 & 4 & $(0.30)$ & 74.5 \\
\hline Brain \& Nervous system & 1 & $(0.10)$ & 62 & 2 & $(0.30)$ & 65.5 & 3 & $(0.20)$ & 64.3 \\
\hline Eye & 2 & $(0.20)$ & 60 & 2 & $(0.30)$ & 87 & 4 & $(0.30)$ & 78,0 \\
\hline Pancreas & 1 & $(0.10)$ & 60 & 2 & $(0.30)$ & 60.5 & 3 & $(0.20)$ & 60.3 \\
\hline Tonsil & 2 & $(0.20)$ & 75.5 & 1 & $(0.20)$ & 80 & 3 & $(0.20)$ & 77 \\
\hline Vagina & 0 & & & 3 & $(0.50)$ & 69 & 3 & $(0.20)$ & 69 \\
\hline Oropharynx & 2 & $(0.20)$ & 68.5 & 1 & $(0.20)$ & 82 & 3 & $(0.20)$ & 73 \\
\hline $\mathrm{HL}$ & 3 & $(0.30)$ & 66.3 & & & & 3 & $(0.20)$ & 66.3 \\
\hline Others & 14 & (1.60) & & 6 & $(1.00)$ & & 20 & (1.40) & - \\
\hline Total & 871 & (100) & & 593 & (100) & & 1464 & (100) & 70.4 \\
\hline
\end{tabular}

NS (Nervous system); NHL (Non-hodgkins lymphoma); HL (Hodgkins lymphoma);Yrs (years) 
the study center serves as a major referral center to both Delta and Edo States of Nigeria. The most likely explanation for the abrupt drop in the number of cases is the competing interest from Delta State University Teaching Hospital, which has increased its capacity and therefore changed the destination of many referred cancer cases, especially among those domiciled in Delta State of Nigeria. In general, it can be concluded that the number of cancer cases has continued to increase among the Nigerian elderly patients. Our rate of increase is however comparatively lower than might be seen in developed countries like Europe and Asia where older adults of 65+ years constitute about $22-39 \%$ of the population, where population ageing is much higher [18].

In this study, males had a higher cancer burden than females with a male to female ratio of $1.5: 1$, which compared favorably with 2.1:1 reported in Akwa-Ibom but at variance with 1.9:2 reported in Port Harcout, Nigeria.
[10-11]. In a worldwide study across 184 countries, an excess of cancer in elderly males was a general observation with a male to female ratio of 1.1-19:1 [18]. This male excess is even greater than its face value since globally, there are consistently, substantially more elderly females than males in every region [19]. Some explanation to the sex discrepancy may be provided by the differences in biology, gender role and carcinogen exposure. Men play more of productive roles while the women played more of reproductive roles at the early stage of their life cycles. The gender role further influences men's exposure to occupational carcinogens, exposure to sunlight, smoking, alcohol abuse, unhealthy diets and higher levels of stress. Most of these cancer associated with these risk factors manifest much later in life [20].

There is a marked variation in the topographic distribution of cancer in this report. In the entire study, the leading cancer were prostate, colorectal, stomach,

Table 2. Age Profile of Geriatric Cancer among Organs

\begin{tabular}{|c|c|c|c|c|c|c|c|c|c|c|}
\hline \multirow[t]{2}{*}{ Site/Organ } & \multicolumn{9}{|c|}{ Age Group in Years } & \multirow[t]{2}{*}{ NO } \\
\hline & $60-64$ & $65-69$ & $70-74$ & $75-79$ & $80-84$ & $85-89$ & $90-94$ & $95-99$ & $100-104$ & \\
\hline Prostate & $95(15.7 \%)$ & $133(22.0 \%)$ & $144(23.8 \%)$ & $121(20.0 \%)$ & $73(12.1 \%)$ & $26(4.3 \%)$ & $10(1.7 \%)$ & $2(0.3 \%)$ & & $604(41.3 \%)$ \\
\hline Cervix & $54(30 \%)$ & $54(30.0 \%)$ & $25(13.9 \%)$ & $25(13.9 \%)$ & $13(7.2 \%)$ & $3(1.6 \%)$ & $3(1.7 \%)$ & $3(1.7 \%)$ & & $180(12.3 \%)$ \\
\hline Breast & $67(37.2 \%)$ & $58(32.2 \%)$ & $25(13.9 \%)$ & $18(10.0 \%)$ & $5(2.8 \%)$ & $3(1.7 \%)$ & & $3(1.7 \%)$ & $1(0.6 \%)$ & $180(12.3 \%)$ \\
\hline Colorectum & $29(34.1 \%)$ & $17(20 \%)$ & $20(23.5 \%)$ & $8(9.4 \%)$ & $8(9.4 \%)$ & $3(3.5 \%)$ & & & & $85(5.8 \%)$ \\
\hline Stomach & $10(21.7 \%)$ & $11(23.9 \%)$ & $5(10.9 \%)$ & $10(21.7 \%)$ & $7(15.2 \%)$ & & $2(6.5 \%)$ & 1 & & $46(3.1 \%)$ \\
\hline Nose, sinuses & $13(36.1 \%)$ & $13(36.1 \%)$ & $4(11.1 \%)$ & $2(5.6 \%)$ & $1(2.8 \%)$ & $2(5.6 \%)$ & & & $1(2.8 \%)$ & $36(2.5 \%)$ \\
\hline Bladder & $12(33.3 \%)$ & $4(12.1 \%)$ & $6(18.2 \%)$ & $7(21.2 \%)$ & $3(9.1 \%)$ & $2(6.1 \%)$ & & & & $33(2.3 \%)$ \\
\hline NMSC & $8(26.7 \%)$ & $7(23.3 \%)$ & $6(20.0 \%)$ & $3(10.0 \%)$ & $3(10.0 \%)$ & $2(6.7 \%)$ & & $1(3.3 \%)$ & & $30(2.1 \%)$ \\
\hline Uterine corpus & $14(53.9 \%)$ & $8(30.8 \%)$ & $2(7.7 \%)$ & $1(3.9 \%)$ & $1(3.9 \%)$ & & & & & $26(1.8 \%)$ \\
\hline Larynx & $11(44.0 \%)$ & $3(12.0 \%)$ & $9(36.0 \%)$ & & & $1(4.0 \%)$ & $1(4.0 \%)$ & & & $25(1.7 \%)$ \\
\hline Lung & $4(18.2 \%)$ & $8(36.4 \%)$ & $9(40.9 \%)$ & $1(4.6 \%))$ & & & & & & $22(1.5 \%)$ \\
\hline NHL & $12(44.4 \%)$ & $7(27.3 \%)$ & $3(11.1 \%)$ & $4(14.8 \%)$ & & $1(4.6 \%)$ & & & & $27(1.8 \%)$ \\
\hline Esophagus & $5(27.8 \%)$ & $6(33.3 \%)$ & $1(5.6 \%)$ & $5(27.8 \%)$ & $1(5.6 \%)$ & & & & & $18(1.2 \%)$ \\
\hline Kaposi & $6(33.3 \%)$ & $7(38.9 \%)$ & $2(11.1 \%)$ & $3(16.7 \%)$ & & & & & & $18(1.2 \%)$ \\
\hline Ovary & $6(37.5 \%)$ & $5(31.3 \%)$ & $2(12.5 \%)$ & $1(6.3 \%)$ & $2(12.5 \%)$ & & & & & $16(1.1 \%)$ \\
\hline Soft tissue & $3(20 \%)$ & $6(40.0 \%)$ & $3(20.0 \%)$ & $1(6.7 \%)$ & $1(6.7 \%)$ & & & & & $15(1.0 \%)$ \\
\hline Vulva & $4(33.3 \%)$ & $4(33.3 \%)$ & $2(16.7 \%)$ & & $1(8.3 \%)$ & & $1(8.3 \%)$ & & & $12(0.8 \%)$ \\
\hline Skin melanoma & $2(20.0 \%)$ & $2(20.0 \%)$ & $2(20.0 \%)$ & $3(30.0 \%)$ & & & & $1(10.0 \%)$ & & $10(0.7 \%)$ \\
\hline Liver & $4(44.4 \%)$ & $3(33.3 \%)$ & $1(11.1 \%)$ & $1(11.1 \%)$ & & & & & & $9(0.6 \%)$ \\
\hline Kidney & $2(25.0 \%)$ & $1(12.5 \%)$ & $1(12.5 \%)$ & $1(12.5 \%)$ & $3(37.5 \%)$ & & & & & $8(0.6 \%)$ \\
\hline Thyroid & $2(25.0 \%)$ & $3(37.5 \%)$ & $1(12.5 \%)$ & & $2(25.0 \%)$ & & & & & $8(0.6 \%)$ \\
\hline Hypopharynx & $2(33.3 \%)$ & $3(50.0 \%)$ & & $1(16.7 \%)$ & & & & & & $6(0.4 \%)$ \\
\hline Salivary gland & $1(25.0 \%)$ & $1(25.0 \%)$ & $1(25.0 \%)$ & & $1(25.0 \%)$ & & & & & $4(0.3 \%)$ \\
\hline Small intestine & & $1(25.0 \%)$ & $1(25.0 \%)$ & $1(25.0 \%)$ & $1(25.0 \%)$ & & & & & $4(0.3 \%)$ \\
\hline Eye and orbit & $(50.00 \%)$ & & & & $1(25.0 \%)$ & & $1(25.0 \%)$ & & & $3(0.2 \%)$ \\
\hline Oropharynx & & $2(66.7 \%)$ & & & $1(33.3 \%)$ & & & & & $4(0.3 \%)$ \\
\hline Brain\& NS & $2(66.7 \%)$ & $1(33.3 \%)$ & & & & & & & & $3(0.2 \%)$ \\
\hline Pancreas & $3(100 \%)$ & & & & & & & & & $3(0.2 \%)$ \\
\hline Tonsil & $1(33.3 \%)$ & & & & $1(33.3 \%)$ & $1(33.3 \%)$ & & & & $3(0.2 \%)$ \\
\hline Vagina & $1(33.3 \%)$ & $1(33.3 \%)$ & & & $1(33.3 \%)$ & & & & & $3(0.2 \%)$ \\
\hline $\mathrm{HL}$ & $2(66.7 \%)$ & & & $1(33.3 \%)$ & & & & & & $3(0.2 \%)$ \\
\hline Others & $4(20.0 \%)$ & $3(15.0 \%)$ & $5(25.0 \%)$ & $2(10.0 \%)$ & $2(10.0 \%)$ & $2(10.0 \%)$ & $1(5.0 \%)$ & & $1(5.0 \%)$ & $20(1.4 \%)$ \\
\hline Total no & 381 & 372 & 280 & 220 & 132 & 47 & 19 & 11 & 3 & 1464 \\
\hline$\%$ of all cancer & $26.00 \%$ & $25.40 \%$ & $19.10 \%$ & $15.00 \%$ & $9.00 \%$ & $3.20 \%$ & $1.30 \%$ & $0.80 \%$ & $0.20 \%$ & $100 \%$ \\
\hline
\end{tabular}

NMSC, Non-melanoma skin cancer; NS, Nervous system; HL, Hodgkins lymphoma 


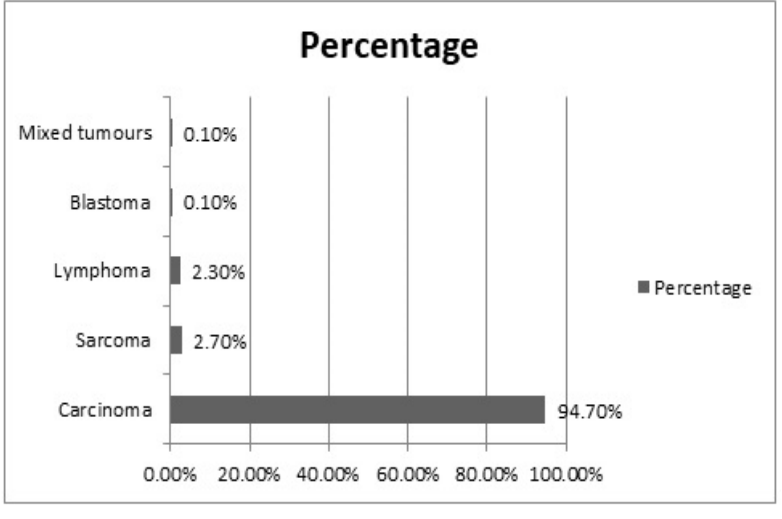

Figure 3. Distribution of Geriatric Cancers into Histologic Groups

laryngeal and nasopharyngeal cancer for males and cervical, breast, colorectal, uterine corpus and stomach cancer for females (in decreasing order). Earlier studies on geriatric cancer epidemiology show striking differences in distribution of contributors of cancer in various regions, across the globe, as highlighted in Tables 3 and 4 [21-26]. In this study, the observation of prostate cancer as the leading cancer among elderly males is in concordance with earlier reports that prostate cancer is the most common cancer in most countries [1]. In an analysis of cancer among older men by Pilleron et al., prostate cancer was also the most common globally, except in some Asian countries [18]. Although the risk factors for prostate cancer have been poorly characterized, early detection has been associated with marked reduction in mortality, especially when backed up with effective treatment [1]. Conversely, lung cancer, which was shown to be one of the leading cancers in most developed countries among the elderly in other regions, is uncommon in our region, possibly due to differences in tobacco consumption and genetic factors [1-18]. Among older women in this study, cancer of the uterine cervix is the most common cancer, which is at variance with reports from non-African countries [1-18]. Africa has been the major contributor of the global burden of cervical cancer because national cervical cancer screening programmes and vaccination against the oncogenic strain of human papilloma virus have remained an abysmal failure. On the contrary, the adoption of these activities in most developed countries is the major explanation for the consistent decline in cervical cancer in these regions in recent decades [1-18]. Across the globe, breast cancer is the most common cancer among elderly women, except in China and Africa where it is preceded by lung and cervical cancer respectively [18]. The almost consistently high rate of breast cancer in the elderly females in most countries could be a reflection of decreasing parity and the obesity epidemic. A unique pattern in our investigation is that sex-specific cancer (male genital tract cancer among elderly males and breast and female genital tract cancer among elderly females) accounted for over $70 \%$ of cancer in the elderly.

Colorectal cancer accounted for $5.8 \%$ of the geriatric cancer burden in this study and is the second most common among elderly males and third most common among elderly females. Among elderly females, it is also the second most common in Turkey, China and Denmark and the third most common in the US [22-25]. Among elderly males, it is the third most common in the US and Denmark and the fourth most common in Turkey and Kenya [22-24,26]. The close epidemiological pattern may be explained by the change to a westernized low fiber diet, which is a major risk factor for colorectal cancer. Reduction in colorectal cancer incidence and mortality in developed countries is a general observation and is attributed to cancer screening programmes using routine fecal occult blood and colonoscopic examination, which allows for detection and removal of premalignant lesions. [1-18]. These preventive measures are yet to be widely implemented in Nigeria.

With respect to age distribution, the peak occurred at the beginning of the study and decreased continually till the end. Individually, apart from prostate cancer, most cancer peaked right from the 60-64 years age group in this study. Earlier studies had shown that most cancers peaked much earlier than the age of 60 years [27]. The implication for policy makers and legislators is that planning of cancer prevention through public enlightenment on behavioral changes and risk factor modification, cancer screening and vaccination, should target much younger age groups as carcinogenesis is a multi-step evolving process that

Table 3. Comparative Incidence of Top 5 Male Geriatric Cancers Across the World

\begin{tabular}{|c|c|c|c|c|c|}
\hline \multirow[t]{2}{*}{ Country } & \multicolumn{5}{|c|}{ Descending Order of Cancer Incidence } \\
\hline & 1 & 2 & 3 & 4 & 5 \\
\hline $\mathrm{USA}^{22}$ & Prostate & Lung/Bronchus & Colon & Bladder & Skin melanoma \\
\hline Denmark $^{23}$ & Prostate & Lung/Bronchus & Colon & Stomach & Bladder \\
\hline Turkey $^{24}$ & Lung/Bronchus & Prostate & Bladder & Colon & Stomach \\
\hline China $^{25}$ & Lung/Bronchus & Stomach & Colon & Esophagus & Liver \\
\hline India $^{21}$ & Lung/Bronchus & Prostate & Esophagus & Larynx & Liver \\
\hline Kenya ${ }^{26}$ & Prostate & Esophagus & Stomach & Colon & Nasopharynx \\
\hline South Africa ${ }^{26}$ & Esophagus & Prostate & Lung/Bronchus & Lips/Oral & Larynx \\
\hline Uganda $^{26}$ & Prostate & Esophagus & Nasopharynx & Kaposi & Stomach \\
\hline Zimbabwe $^{26}$ & Prostate & Stomach & Esophagus & TBL & Nasopharynx \\
\hline Index study & Prostate & Colon & Stomach & larynx & Nasopharynx \\
\hline
\end{tabular}


Table 4. Comparative Incidence of 5 Top Female Geriatric Cancer Across the World

\begin{tabular}{|c|c|c|c|c|c|}
\hline \multirow[t]{2}{*}{ Country } & \multicolumn{5}{|c|}{ Order of Cancer Inidence } \\
\hline & 1 & 2 & 3 & 4 & 5 \\
\hline $\mathrm{USA}^{22}$ & Breast & Lung/Bronchus & Colon & Corpus uteri & NHL \\
\hline Denmark $^{23}$ & Breast & Colon & Lung/Bronchus & Stomach & Corpus uteri \\
\hline Turkey $^{24}$ & Breast & Colon & Stomach & Lung/Bronchus & Corpus uteri \\
\hline China $^{25}$ & Lung & Colon & Breast & Esophagus & Liver \\
\hline India $^{21}$ & Breast & Cervix & Ovary & Esophagus & Lung \\
\hline Kenya $^{26}$ & Breast & Cervix & Esophagus & Stomach & Ovary \\
\hline South Africa ${ }^{26}$ & Cervix & Esophagus & Breast & Corpus uteri & Liver \\
\hline Uganda $^{26}$ & Cervix & Breast & Esophagus & Liver & Ovary \\
\hline Zimbabwe $^{26}$ & Cervix & Breast & Stomach & Esophagus & Liver \\
\hline Index study & Cervix & Breast & Colon & Corpus uteri & Stomach \\
\hline
\end{tabular}

should be terminated early.

Carcinoma is the most common geriatric malignancy in this study, accounting for $94.7 \%$ of the cancer. This is expected because the major organs accounting for cancer in the elderly are lined by epithelial cells. Sarcoma is the second most common groups of cancer, accounting for $2.7 \%$ of the cancer burden. Interestingly, the most common sarcoma in this region is Kaposi sarcoma, which also has an overwhelming male predominance. Although increasing rate of Kaposi sarcoma were attributed to HIV infection in an earlier study,[28] the relationship in this study was not confirmed.

Non Hodgkin's lymphoma was relatively more common than Hodgkin's lymphoma in this study. Literature on lymphoma among Nigerian elderly is however scanty.

In this part of the globe, where environmental hygiene is poor and infection is still a major health challenge, a high incidence of infection related cancer is not unexpected. This may explain why cervical cancer (Human papilloma virus), stomach cancer (Helicobacter pylori), liver cancer (hepatitis $\mathrm{B}$ and $\mathrm{C}$ virus), nasopharyngeal cancer (Epstein-Barr virus), and Kaposi sarcoma (Human immunodeficiency virus) are common in this region. Improving hygiene and vaccination where possible, will go a long way in reversing this trend.

Despite the current cancer burden in the elderly, there are many impediments to the fight against geriatric cancer. These include poverty and low socioeconomic status of the elderly, absence of social security for senior citizens, negative cultural belief systems, high treatment costs, dwindling family support arising from westernized lifestyle and the collapsing extended family system, outof-pocket payment of hospital bills, belief in traditional medicine and faith therapy, the presence of few standard oncology treatment centers with qualified personnel and necessary infrastructure for optimal care of cancer patients, the current brain drain arising from mass exodus of qualified personnel in search of greener pastures and above all, the lack of political will to develop geriatric oncology in this most populous country of Africa [29-30].

There is no better time for a radical solution than now, if the geriatric cancer crisis has to be prevented from growing out of control. Both individuals and the government have roles to play. Public health education campaigns against cancer-promoting life styles (such as smoking, alcohol consumption and unhealthy diet, obesity and physical inactivity), and the elimination of stigma, misinformation and misconception are invaluable. There is need for a national framework on preventive measures against cancer through vaccination and treatment against hepatitis $B$ and $C$ viruses, human immunodeficiency virus, Helicobacter pylori and Human papilloma virus as well as screening and for cervical, breast, colorectal and prostate cancer. Treatment of cancer is financially intensive; therefore universal health insurance should be adopted to bridge this gap. The current healthcare budget has to be increased to improve existing health infrastructure and promote training and research in geriatric oncology. It is time for high profile cancer institution across the globe to mentor and collaborate with Nigerian institutions, especially the National Postgraduate Medical College and the West African College of Physicians to promote training of certified geriatric health care personnels. This is the time to approach donor agencies, international philanthropic organizations and explore public-private partnerships to assist in strengthening our weak health system. While the government should be encouraged to ensure that the Nigerian environment becomes more attractive to young doctors, there is need for its citizens to be more patriotic. This will go a long way to prevent the current brain drain. At local level, there is need for interdisciplinary co-ordination of care and greater personal commitment among health workers towards this goal. The time for the paradigm shift is now [29].

\section{Limitation}

Our study is a hospital based pathologic analysis. It therefore excludes cancer cases diagnosed using other techniques such as imaging. It also excludes cases diagnosed and managed in other healthcare centers in this region. These factors may lower the epidemiological significance of this report.

In conclusion, the Nigerian elderly have a considerable cancer burden, with over $70 \%$ of them arising from the prostate, uterine cervix, breast, colorectum and stomach. 
Geriatric cancer incidence is on the increase with a peak at $60-64$ years. It is more common in males and seems to be dominated by sex-specific cancers, and infection related cancer. Geriatric cancer care is still a low priority in Nigeria. A stronger health and social system is desirable for the worsening geriatric cancer burden in this region.

\section{Acknowledgements}

The authors are highly indebted to the staff and management of the Department Pathology of the University of Benin Teaching Hospital, Benin City, Nigeria.

\section{Funding statement}

Funding was by both authors. There was no external support.

\section{References}

1. Bray F, Ferlay J, Soerjomataram I, Siegel RL, Torre LA, Jemal A. Global cancer statistics 2018: GLOBOCAN estimates of incidence and mortality worldwide for 36 cancers in 185 countries. CA: A Cancer Journal for Clinicians. 2018 09 12;68(6):394-424. https://doi.org/10.3322/caac.21492

2. Aunan JR, Cho WC, Søreide K. The Biology of Aging and Cancer: A Brief Overview of Shared and Divergent Molecular Hallmarks. Aging and Disease. 2017;8(5):628. https://doi.org/10.14336/ad.2017.0103

3. CINAR D. Cancer in the Elderly. Northern Clinics of Istanbul. 2015;. https://doi.org/10.14744/nci.2015.72691

4. Williams GR, Mackenzie A, Magnuson A, Olin R, Chapman A, Mohile S, Allore H, Somerfield MR, Targia V, Extermann M, Cohen HJ, Hurria A, Holmes H. Comorbidity in older adults with cancer. Journal of Geriatric Oncology. 2016 07;7(4):249-257. https://doi.org/10.1016/j.jgo.2015.12.002

5. Kansal S, Rao S. Demographic transition - Cancer trends in geriatric population of North India. Journal of Geriatric Oncology. 2019 03;10(2):362-364. https://doi.org/10.1016/j. jgo.2018.07.011

6. Jedy-Agba EE, Oga EA, Odutola M, Abdullahi YM, Popoola A, Achara P, Afolayan E, Banjo AAF, Ekanem I, Erinomo O, Ezeome E, Igbinoba F, Obiorah C, Ogunbiyi O, Omonisi A, Osime C, Ukah C, Osinubi P, Hassan R, Blattner W, Dakum P, Adebamowo CA. Developing National Cancer Registration in Developing Countries - Case Study of the Nigerian National System of Cancer Registries. Frontiers in Public Health. 201507 30;3. https://doi.org/10.3389/ fpubh.2015.00186

7. Tanyi PL, André P, Mbah P, Tong K. Care of the elderly in Nigeria: Implications for policy. Cogent Social Sciences. $20180101 ; 4(1): 1555201$. https://doi.org/10.1080/233118 86.2018.1555201

8. WHO. Proposed working definition of an older person in Africa for the MDS Project. Available at: https://www.who. int/healthinfo/survey/ageingdefnolder/en/..

9. Jacques Ferlay, Klaus Kraywinkel, Brian Rous, Ariana Znaor. Classification and coding. In: International Agency for Research on Cancer/WHO. Cancer incidence in five continents Volume XI. Available at https://ci5.iarc.fr/CI5$\mathrm{XI} /$ Default.aspx..

10. Obiora C, Osagbemiro B, Akani N. Cancer incidence in the Niger Delta region of Nigeria. A population based review of Port Harcourt Cancer registry. TNHJ. 2018;19(2):85-94.
11. Nwafor C, Nwafor N. The pattern and distribution of cancers in Akwa Ibom State, Nigeria. Nigerian Journal of Clinical Practice. 2018;21(5):603. https://doi.org/10.4103/njcp. njcp_316_17

12. Jedy-Agba E, Curado MP, Ogunbiyi O, Oga E, Fabowale T, Igbinoba F, Osubor G, Otu T, Kumai H, Koechlin A, Osinubi P, Dakum P, Blattner W, Adebamowo CA. Cancer incidence in Nigeria: A report from population-based cancer registries. Cancer Epidemiology. 2012 Oct;36(5):e271-e278. https:// doi.org/10.1016/j.canep.2012.04.007

13. Laryea DO, Awuah B, Amoako YA, Osei-Bonsu E, Dogbe J, Larsen-Reindorf R, Ansong D, Yeboah-Awudzi K, Oppong JK, Konney TO, Boadu KO, Nguah SB, Titiloye NA, Frimpong NO, Awittor FK, Martin IK. Cancer incidence in Ghana, 2012: evidence from a population-based cancer registry. BMC Cancer. 201405 23;14(1). https://doi. org/10.1186/1471-2407-14-362

14. Darré T, Walla A, Kpatcha TM, Aboubakari A, Maneh N, Koulinga M, Amégbor K, Koura GN. Cancers in the Elderly Seen in Anatomical Pathology Laboratory in Lom\&\#233; Togo. Open Journal of Pathology. 2016;06(01):26-31. https:// doi.org/10.4236/ojpathology.2016.61005

15. Zou XN, Wan X, Dai Z, Yang GH. Epidemiological Characteristics of Cancer in Elderly Chinese. ISRN Oncology. 2012 Dec 30;2012:1-5. https://doi.org/10.5402/2012/381849

16. Yancik R. Cancer burden in the aged. Cancer. 1997 Oct 01;80(7):1273-1283. https://doi.org/10.1002/(sici)10970142(19971001)80:7<1273::aid-cncr13>3.0.co;2-4

17. Nkoua M'Bon J, Nsondé Malanda J, Moukassa D. Cancers in the Elderly in Brazzaville. Carcinol Clin Afrique. 2011;10:43-6.

18. Pilleron S, Sarfati D, Janssen-Heijnen M, Vignat J, Ferlay J, Bray F, Soerjomataram I. Global cancer incidence in older adults, 2012 and 2035: A population-based study. International Journal of Cancer. 2018 Oct 30;144(1):49-58. https://doi.org/10.1002/ijc.31664

19. Guralnik JM, Balfour JL, Volpato S. The ratio of older women to men: Historical perspectives and cross-national comparisons. Aging Clinical and Experimental Research. 2000 04;12(2):65-76. https://doi.org/10.1007/bf03339893

20. Cook MB, Dawsey SM, Freedman ND, Inskip PD, Wichner SM, Quraishi SM, Devesa SS, McGlynn KA. Sex Disparities in Cancer Incidence by Period and Age. Cancer Epidemiology Biomarkers \& Prevention. 200903 17;18(4):1174-1182. https://doi.org/10.1158/1055-9965. epi-08-1118

21. Yeole B, Kurkure A, Koyande S. Geriatric Cancers in India: An Epidemiological and Demographic Overview. Asian Pacific J Cancer Prev. 2008;9:271-4.

22. White MC, Holman DM, Goodman RA, Richardson LC. Cancer Risk Among Older Adults: Time for Cancer Prevention to Go Silver. The Gerontologist. 201905 17;59(Supplement_1):S1-S6.https://doi.org/10.1093/geront/ gnz038

23. Hansen J. Common Cancers in the Elderly. Drugs \& Aging. 1998;13(6):467-478. https://doi.org/10.2165/00002512199813060-00005

24. CINAR D. Cancer in the Elderly. Northern Clinics of Istanbul. 2015;. https://doi.org/10.14744/nci.2015.72691

25. Li S, Zhang X, Yan Y, Wang K, Rui D, Pang L, Li F. High Cancer Burden in Elderly Chinese, 2005-2011. International Journal of Environmental Research and Public Health. 201509 29;12(10):12196-12211. https://doi.org/10.3390/ ijerph121012196

26. Pilleron S, Soerjomataram I, Charvat H, Chokunonga E, Somdyala NIM, Wabinga H, Korir A, Bray F, Jemal A, Maxwell Parkin D. Cancer incidence in older adults 
in selected regions of sub-Saharan Africa, 2008-2012. International Journal of Cancer. 201901 11;144(8):18241833. https://doi.org/10.1002/ijc.31880

27. Uchendu OJ. Cancer Incidence in Nigeria: A Tertiary Hospital Experience. Asian Pacific Journal of Cancer Care. 202002 10;5(1):27-32. https://doi.org/10.31557/ apjcc.2020.5.1.27-32

28. Onunu AN, Okoduwa C, Eze EU, Adeyekun AA, Kubeyinje EP, Schwartz RA. Kaposi's sarcoma in Nigeria. International Journal of Dermatology. 2007 03;46(3):264-267. https://doi. org/10.1111/j.1365-4632.2007.03016.x

29. Boyle P, Ngoma T, Sullivan R, Ndlovu N, Autier P, Stefan C, et al. The State of Oncology in Africa 2015; International Prevention Research Institute, Lyon.:1-560.

30. Ike S. The health workforce crisis: the brain drain scourge. Niger J Med. 2007;16(3):204-11.

\section{(c) (i) (8)}

This work is licensed under a Creative Commons AttributionNon Commercial 4.0 International License. 